\title{
Intestinal steatosis in the farm-reared sea bass Dicentrarchus labrax
}

\author{
M. Deplano, R. Connes*, J. P. Diaz, J. Paris \\ Laboratoire de Biologie animale, U.S.T.L., F-34060 Montpellier Cedex, France
}

\begin{abstract}
Light microscopy, scanning and transmission electron microscopy were used to study the anterior intestine of the sea bass Dicentrarchus labrax L., involved in lipid absorption. In the first part of the study, intestinal morphology of control feral fishes was described and lipid absorption through the intestinal mucosa was defined by comparing starved and fed individuals. In the second part, similar investigations were made on specimens reared on artificial food. These show injuries of the mucosa, ranging from simple impairment of enterocytic striated border to cellular necrosis and abrasion. The severity of injuries was related to the extent of lipid overloading within the mucosa. This overloading was mainly represented by abundant lipid droplets in epithelial cells, and by the accumulation of numerous and large lipid granules in interenterocytic spaces and in the lamina propria. Possible influences of artificial feed on this digestive pathology are discussed from quantitative and qualitative points of view.
\end{abstract}

\section{INTRODUCTION}

To meet economic demands and obtain greater costeffectiveness, most fish breeders resort to intensive farming techniques, using commercial granulated feed as sole food source. Considering the importance of nourishment in attaining ideal growth, the success of such farms is highly related to a careful choice of food. The nutritional requirements of certain freshwater species such as trout are now relatively well known, notably with respect to the lipid fraction, but the same cannot be said of marine species. Ignorance of specific food requirements leads to the use of unsuitable food and is the source of various degrees of abnormality, as reported in certain farm-bred fishes. The studies by Eckmann (1985) on Coregonus sp. and by Segner et al. (1987) on Chanos chanos revealed intestinal histopathology of larvae combined with malnutrition. In fish, most of these abnormalities have been studied in the liver (Bac et al. 1983, Storch et al. 1984, Segner 1985), and have consistently suggested disturbances in lipid metabolism. In mammals, Snipes (1968) has attributed profound changes in the epithelial cells of the jejunum to defective fat absorption related to dietary deficiencies in essential fatty acids.

\footnotetext{
- Addressee for reprint requests
}

For several years we have participated in the sanitary inspection of immature farm-bred fish of the $0^{+}$class (less than 1 yr old), an age generally considered by fish-breeders as a critical period of life. We have often observed lesions in these fish's digestive mucosa, whose causes and consequences are still difficult to assess. Preliminary research on some of the lesions has been carried out in sea bream Sparus auratus (Diaz et al. 1987). The purpose of the present work on sea bass Dicentrarchus labrax, a carnivorous fish with stomach, was to study in detail the deterioration of the proximal intestine, which is the site of lipid absorption, and to relate it as far as possible to disturbances in this phase of digestion. Many studies in mammals, particularly in humans, have shown links between histopathologies of the intestinal epithelium and natural or induced disturbances in fat digestion and absorption (Sabesin \& Isselbacher 1965, Dobbins 1966, Shimoda et al. 1968, Rubin 1971, Ament et al. 1972, Friedman \& Cardell 1977, Takahashi \& Mizunuma 1984).

\section{MATERIALS AND METHODS}

Immature farm-bred sea bass Dicentrarchus labrax L., less than 1 yr old $\left(0^{+}\right)$, but with an adult-like alimentary tract, were provided by the IFREMER station at Palavas (Hérault, France). Raised in cages submerged 
in the Prévost lagoon, they received an artificial feed containing $12 \%$ lipid, chiefly fish oil (Brichon pers. comm.) distributed manually Twenty farm-reared fish were studied from September to December Their standard body lengths ranged from 88 to $178 \mathrm{~mm}$; total body weight ranged from 13.2 to $98.2 \mathrm{~g}$. Seven control specimens living in natural environment, and of the same length and weight groups as the reared fish, were captured in October and November with fishing lines near Sète and Palavas. To obtain valid comparisons with the fish raised and fed in cages, we selected controls whose digestive tract was filled with shrimp and fish when they were killed. Some were killed after a week of starvation.

All fish were decapitated and dissected immediately after removal from the water, and their intestine was fixed on location. Samples of proximal intestine used for this work were removed along with the pyloric caeca. Material for light microscopy was fixed in alcoholic Bouin's fluid and embedded in paraffin. Sections were stained with Masson's trichrome. For electron microscopy, specimens were fixed with $2.5 \%$ glutaraldehyde in a $0.1 \mathrm{M}$ cacodylate buffer, $\mathrm{pH} 7.2$, followed by postfixation with $1 \%$ osmium tetroxide in a 0.3 I $M$ cacodylate buffer, $\mathrm{pH}$ 7.2. Samples for scanning electron microscopy (SEM) were dried by the criticalpoint method and metallized.

For transmission electron microscopy (TEM), material was embedded in epon and the ultra-thin sections were contrasted with uranyl acetate and bismuth oxynitrate. Sudan Black was used to detect lipids in semithin sections.

\section{RESULTS}

The sea bass intestine was found to be composed of 2 specific absorptive regions, anterior and posterior Along the anterior intestine $180 \%$ of the total intestinal length), which is concerned with lipid absorption, the size of the folds and the absorptive surface decreased from the proximal to the distal part (not described in this work). The posterior intestine ( $20 \%$ of the total intestinal length) was principally involved in the absorption of protein macromolecules.

\section{Proximal intestine of feral bass}

\section{Mucosal structure}

In the feral bass, the mucosa of the proximal intestine was characterized by a contour consisting of large firstorder folds arranged longitudinally, covered with many smaller second-order folds.
SEM at low magnification revealed the arrangement of the folds. The second-order folds, which were convoluted and anastomosed, formed a dense network entirely covering the first-order folds (Fig 1). At higher magnification, spherical droplets of mucus could be seen in slight depressions in the epithelium. Cell boundaries were also faintly visible and the mucosal surface had a very uniform appearance (Fig. 2).

Under a light microscope, the intestinal mucosa was seen to be composed of a simple prismatic epithelium. supported by loose and abundant connective tissue, i.e. the lamina propria. Underneath was a layer of compact connective tissue, or stratum compactum, in contact with muscle tissue and inserted into it by a fine network of collagen fibers. This stratum projected a central process into the lamina propra of each fold; each process was tapered at the tip and surrounded welldeveloped venules, arterioles, and lymphatic vessels (Fig. 3)

Ultrastructurally, the enterocyte of the proximal intestine of the sea bass (Fig. 4) was found to correspond to the classic pattern seen in other fishes. It was covered with evenly implanted microvilli, 1.4 to $2.5 \mu \mathrm{m}$ long; those at the apex of the folds were generally shorter than the others. The cytoplasm just underneath these microvilli contained only a few pinocytotic vesicles. Somewhat below, multivesicular bodies could be seen, as well as dense elements that were probably lysosomal. Spherical and elongated mitochondria were numerous at the base and apex of the cell but were scarce in the vicinity of the nucleus. Endoplasmic reticulum was present at all levels, as well as the lamellar structures, invaginations of the baso-lateral plasma membrane, which are characteristic of fish. The Golgi apparatus in the supranuclear region comprised several dictyosomes producing vacuoles and vesicles, which, in the starved bass, sometimes contained several lipid granules no more than $60 \mathrm{~nm}$ in diameter (Fig. 5). Identical granules could be seen in the endoplasmic reticulum. The epithelial cells lay on a basal lamina 0.05 to 0.1 um thick.

\section{Lipid transit across the mucosa}

Following the free intake of food in a natural environment (which could not be quantitatively assessed but essentially consisted of small shrimp easily identified in the stomach and intestinal contents), the mucosa of the proximal intestine contained many Sudan-stainable lipid inclusions. These lipids were easy to visualize on semi-thin sections. They could be seen in the absorbent epithelial cells, where they formed supranuclear clusters 0.3 to $1.5 \mu \mathrm{m}$ in diameter in the interenterocytic spaces, and in the lamina pro- 
pria, where they formed thin trails extending from apex to the base of the folds (Fig. 6). They completely occupied the lumen of the basal lymphatic vessels (Fig. 8) and were also present between the erythrocytes of the neighboring venules (Fig. 7). As in many fishes (see 'Discussion') ultrastructural study revealed 2 categories of lipids in the epithelium: lipid granules, and others previously described as stellate lipids or 'free' lipid droplets depending on the author. The lipid granules were 30 to $110 \mathrm{~nm}$ in diameter but values midway between these 2 extremes were the most frequent. They resembled the VLDL (very low density lipoproteins) of mammals and were located in the endoplasmic reticulum, in certain supranuclear vesicles detached from the Golgi apparatus (Figs. 9 and 10), and less abundantly in the intercellular spaces and lamellar structures. It should be noted that the latter were much more developed in the nourished fish than in the starved fish. Lipid droplets were found rather rarely in the enterocytes of the feral fish. They gave the appearance of clear homogeneous pools, located in the supranuclear region or at the very base of the cell, and were never larger than $0.5 \mu \mathrm{m}$ in diameter (Fig. 11). Although less frequent, similar structures were found among lipid granules in the lamina propria, the intercellular spaces, and the chyliferous vessels.

\section{Proximal intestine of cage-reared sea bass}

\section{Deterioration of mucosa}

The intestinal mucosa of the cage-bred sea bass was characterized by a decrease in the number of secondary folds and often showed changes resulting in a very large accumulation of lipids both in the epithelium and in the underlying connective tissue (Figs. 12 and 13). Of the studied fish, $95 \%$ showed such accumulation of lipids. SEM revealed superficial signs of this steatosis, a deterioration showing 3 degrees of severity. The first degree corresponded to a disorganization of the epithelial surface characterized by a decrease in the density of microvilli and a disturbance of their arrangement. The enterocytes were of very different size and their boundaries were very distinct (Figs. 14 and 15 ). In certain regions the microvilli had completely disappeared (Figs. 16 and 17). In the second degree, the cells at the apex of the folds had become hypertrophic as a result of fat overloading and had separated from one another, leading to the appearance of necrotic areas (Fig. 18). The third degree was marked by progressive abrasion of the apical enterocytes, which were gradually eliminated in the intestinal lumen. The superficial portion of the lamina propria was thus stripped off and lipid droplets of different sizes (Figs. 19 and 20) had been released from burst cells. Less marked epithelial alterations were also detected in the distal part of the anterior intestine.

Modes of fat overloading

Transmission electron microscopy provided information on the modes of fat overloading and the changes it induced. In the enterocyte, the absorbed lipids appeared in 2 forms, as described above for feral fish, i.e. granules and droplets. The granules, which were about 50 to $400 \mathrm{~nm}$ in diameter, resembled the chylomicrons of mammals. They were contained, singly or grouped, in vesicles at all levels of the cell, arising from the reticulum or the Golgi apparatus. The lipid droplets were subspherical amorphous elements. They resembled the lipid droplets of the feral fish, but were larger (with diameters sometimes exceeding $8 \mu \mathrm{m}$ ) and their contour was more even (Fig. 21). The interenterocytic spaces (Figs. 21 and 22) and the spaces of the lamina propria (Fig. 22) and chyliferous vessels were the site of intense lipid accumulation, causing them to dilate. The highest magnifications showed the heterogeneity of these pools, which resulted from the close juxtaposition of different-sized lipid granules (Fig. 22), often associated with droplets of diameter not more than $1.5 \mu \mathrm{m}$.

Fat overloading in the intestinal mucosa affected the morphology and functioning of the absorbent cells, which were subjected to external and internal stresses induced respectively by the accumulation of lipids in the cytoplasm and in the intercellular spaces. The height of the steatotic enterocytes often exceeded $85 \mu \mathrm{m}$, as opposed to $40 \mu \mathrm{m}$ in the feral fish, and they were sometimes 3 times wider than normal (12 $\mu$ m instead of $4 \mu \mathrm{m})$. The displacement of the organelles caused by the development of lipid droplets was accompanied by a large decrease in the number of mitochondria, a disorganization of the Golgi apparatus, a regression of the rough endoplasmic reticulum, and in extreme cases, nuclear degeneration. The lamellar structures were less developed than in the feral bass and occasionally appeared to form basal stacks of membranes (Fig. 21). The microvilli decreased in height and eventually disappeared. As mentioned above, the enterocytes at the apex of the folds were the most degraded, containing lipids mostly in droplet form.

\section{DISCUSSION}

To assess the impact of farming conditions, specifically artificial feed, on the proximal intestine of the sea bass, we first investigated the characteristics of this region of the digestive tract in feral specimens. Lipid 

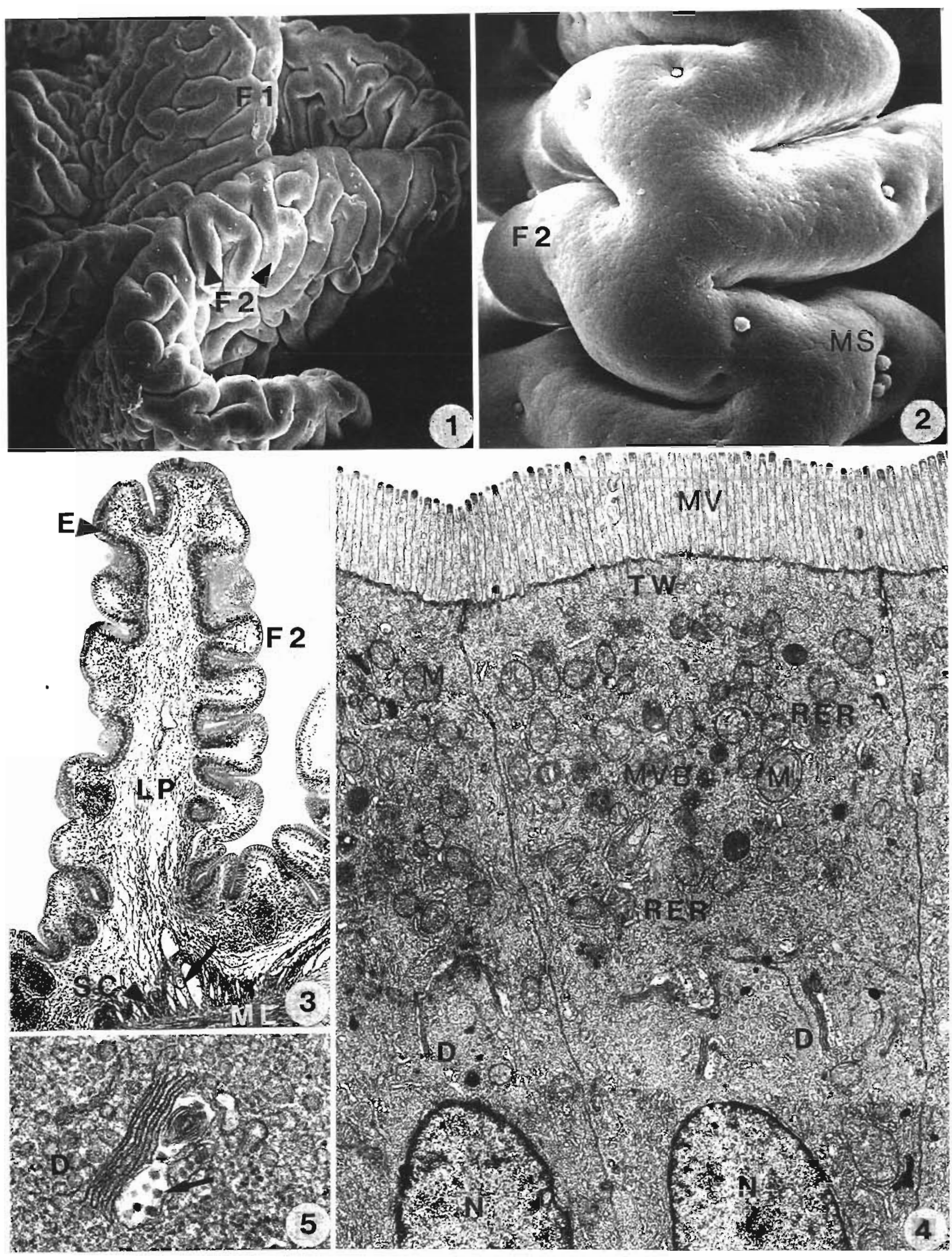

Figs. 1 to 11. Dicentrarchus labrax. Anterior intestine of feral sea bass. Fig. 1. SEM of intestinal mucosa: first-order folds (F1) include convoluted and anastomosed second-order folds $(F 2)$. ( $\times 80)$. Fig. 2 . Higher magnification of apical part of a first-order fold. Note uniformity of the epithelium surface, and presence of mucous secretions (MS). ( $\times 420$ ). Fig. 3. Transverse section through a fold. This light micrograph shows the epithelium (E) supported by the lamina propria (LP). Underneath, a stratum compactum (SC), in contact with the muscular layer (ML), surrounds lymphatic and blood vessels (arrow). ( $\times 120)$. Fig. 4. Ultrastructure of apical part of an enterocyte in a starved fish. Microvilli (MV) are evenly implanted. Mitochondria (M), rough endoplasmic reticulum (RER) and some multivesicular bodies (MVB) are localized between the terminal web (TW) and supranuclear area. In this last zone, several dictyosomes (D) form the Golgi complex. N: nucleus. $(\times 11500)$. Fig. 5. Higher magnification of a dictyosome (D). The external stack contains some VLDL of endogenous origin (arrow). ( $\times 43000)$ 

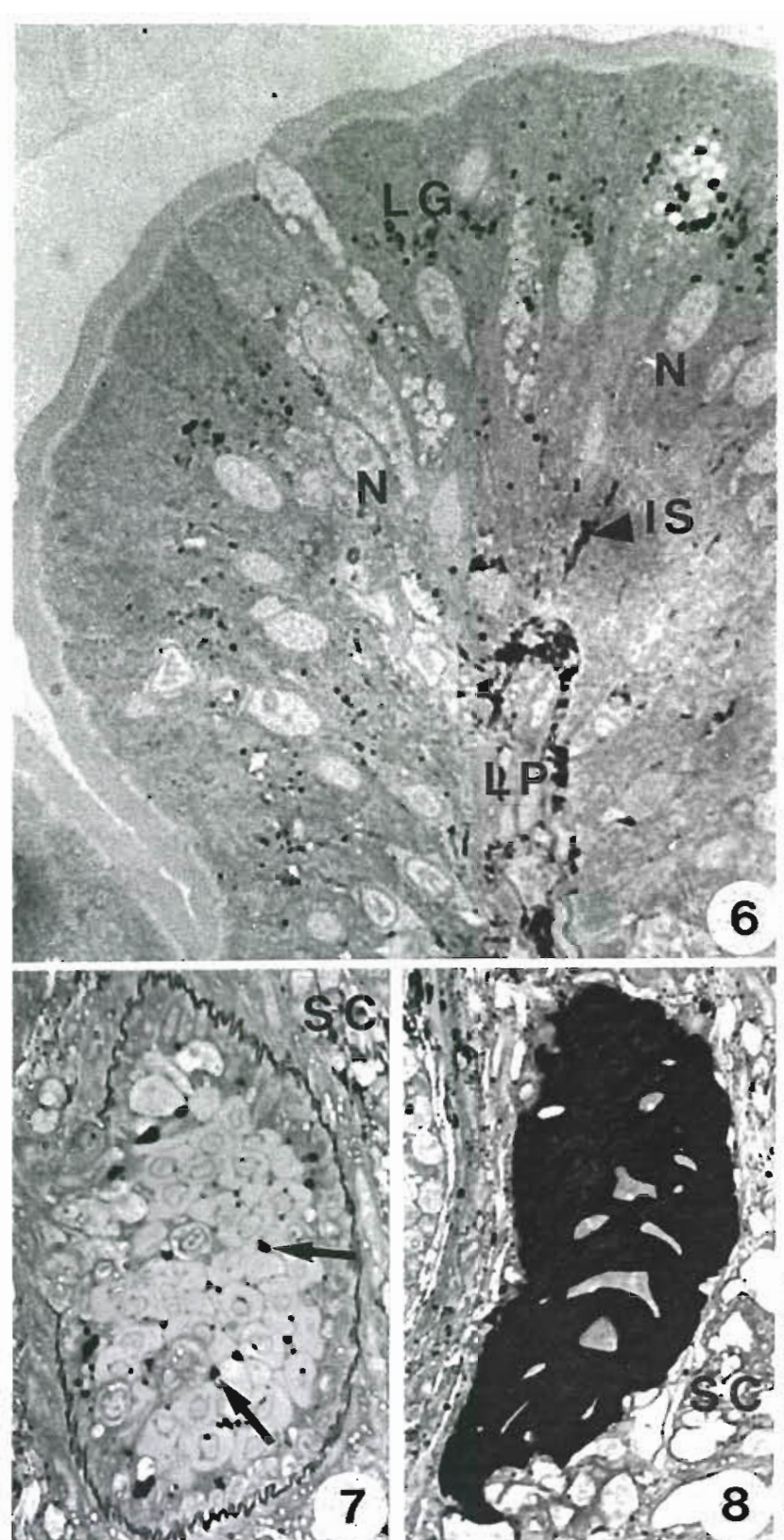

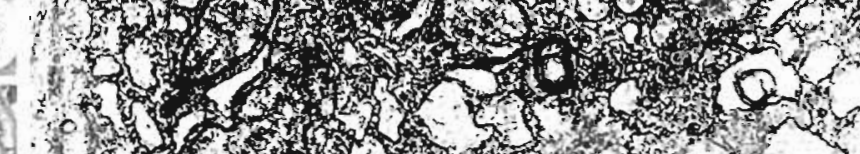

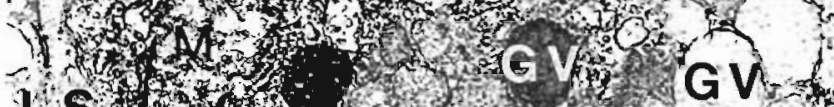

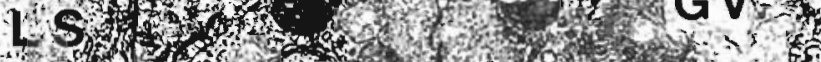

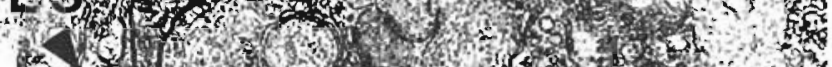
I.

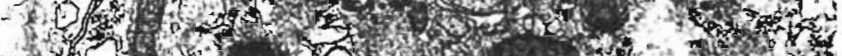

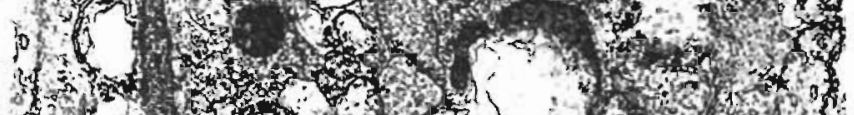

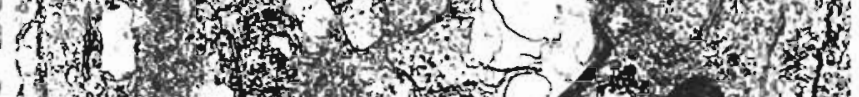

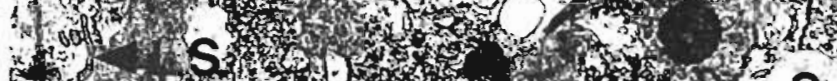

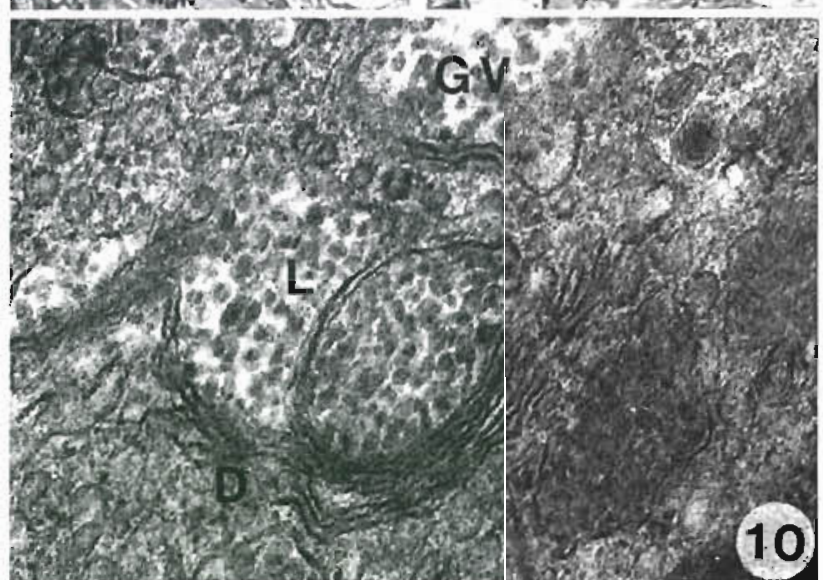

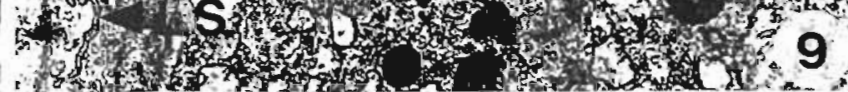

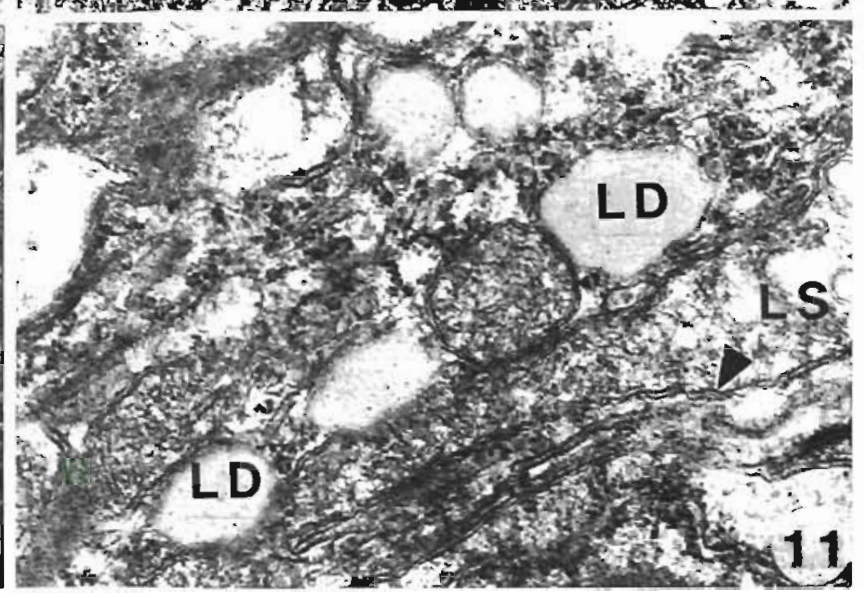

Figs. 1 to 11 (continued). Fig. 6. Sudan-stained semi-thın section with dark absorbed lipıds. These lipıds occur as grains (LG) in the supranuclear area of enterocytes. They are not very abundant in interenterocytic spaces (IS). In the lamina propna (LP) they form a kind of thin trail of infiltration. $(\times 1500)$ Fig 7 Semi-thin section of a venule in the stratum compactum (SC). Sudan-stained elements are visible between erythrocytes (arrows) $(\times 1100)$. Fig. 8 Semi-thin section of a lymphatic vessel in the stratum compactum: its fat contents are strongly Sudan-stamed $(\times 1100)$. Fig. 9. Ultrastructure of the apical part of an enterocyte durnng lipid absorption. In the supranuclear area Golgi vacuoles (GV) are numerous They correspond to dark-staned grains of Fig. 6 . Fat
contents of these vacuoles consist of small-sızed partıcles Simllar particles are also present in the developed and enlarged endoplasmic reticulum (ER). LS: lamellar structure; MV microvilh. TW terminal web (×15000) Flg 10. Detall of a dictyosome (D) containing VLDL-like lipoproteins (L) 30 to $100 \mathrm{~nm}$ in diameter ( $\times 44000$ ) Fig. 11. Detail of 'free hpıd droplets (LD) encountered in the basal pole of an enterocyte. They are scarce and generally small-sized in fed feral fish $(\times 36000)$ 


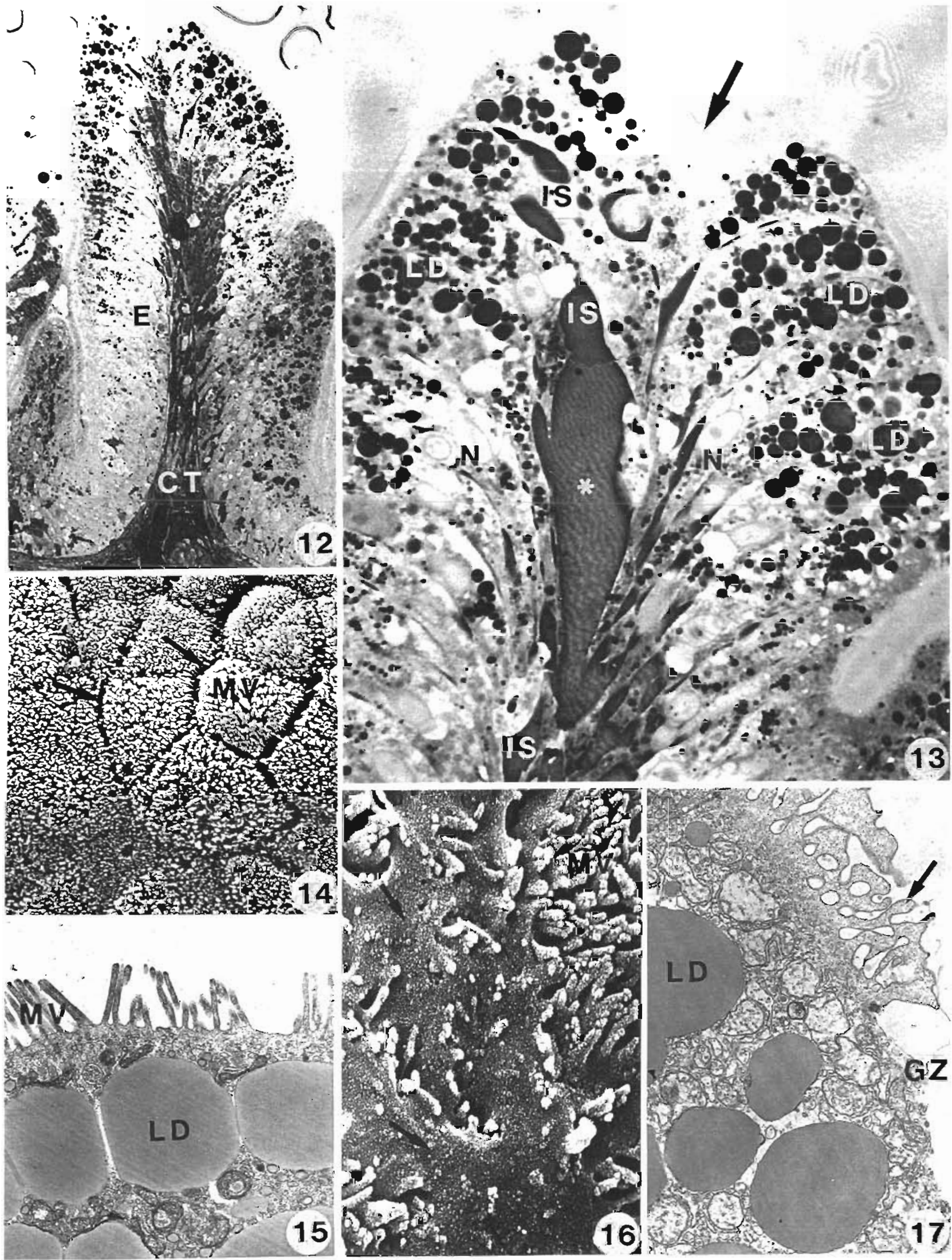

Figs. 12 to 22. Dicentrarchus labrax. Anterior intestine of reared sea bass. Fig. 12. Transverse semi-thin section of a fold stained with Sudan-black. The epithelium (E) and underlying connective tissue (CT) are affected by a medium-marked lipid overloading Scarce secondary folds, in a parallel direction with the section, are less visible than those of feral fish (compare with Fig. 3) $(\times 500)$. Fig. 13. Higher magnification of the top of a fold: in comparison with the wild bass (see Fig. 6), lipids are far more abundant. In absorbing cells, they principally consist of bulky droplets (LD). In intercelinlar spaces (IS) lipids sometimes form very large pools $(*)$. Note the presence of disjoined enterocytes in the apical part of the fold (arrow). ( $\times 1500)$. Fig. 14. Steatotic epithelium in the first degree of seriousness observed with SEM. Remark the presence of disordered microvilli (MV) and the formation of large spaces between the striated borders (arrow). $(\times 2300)$. Fig. 15. Apex of steatotic epitheliocytes in the first degree of severity, observed with TEM. Note decrease in density of microvilli. (MV) (compare with Fig. 5), and presence of fat droplets (LD) $(\times 8200)$. Fig. 16. Other aspects of the disorganization of the epithelial surface, observed with SEM, and characterized by areas devoid of microvilli (arrows). ( $\times 9000$ ). Fig. 17. Previous anomaly observed with TEM, showing a fusion of microvilli (arrow) 

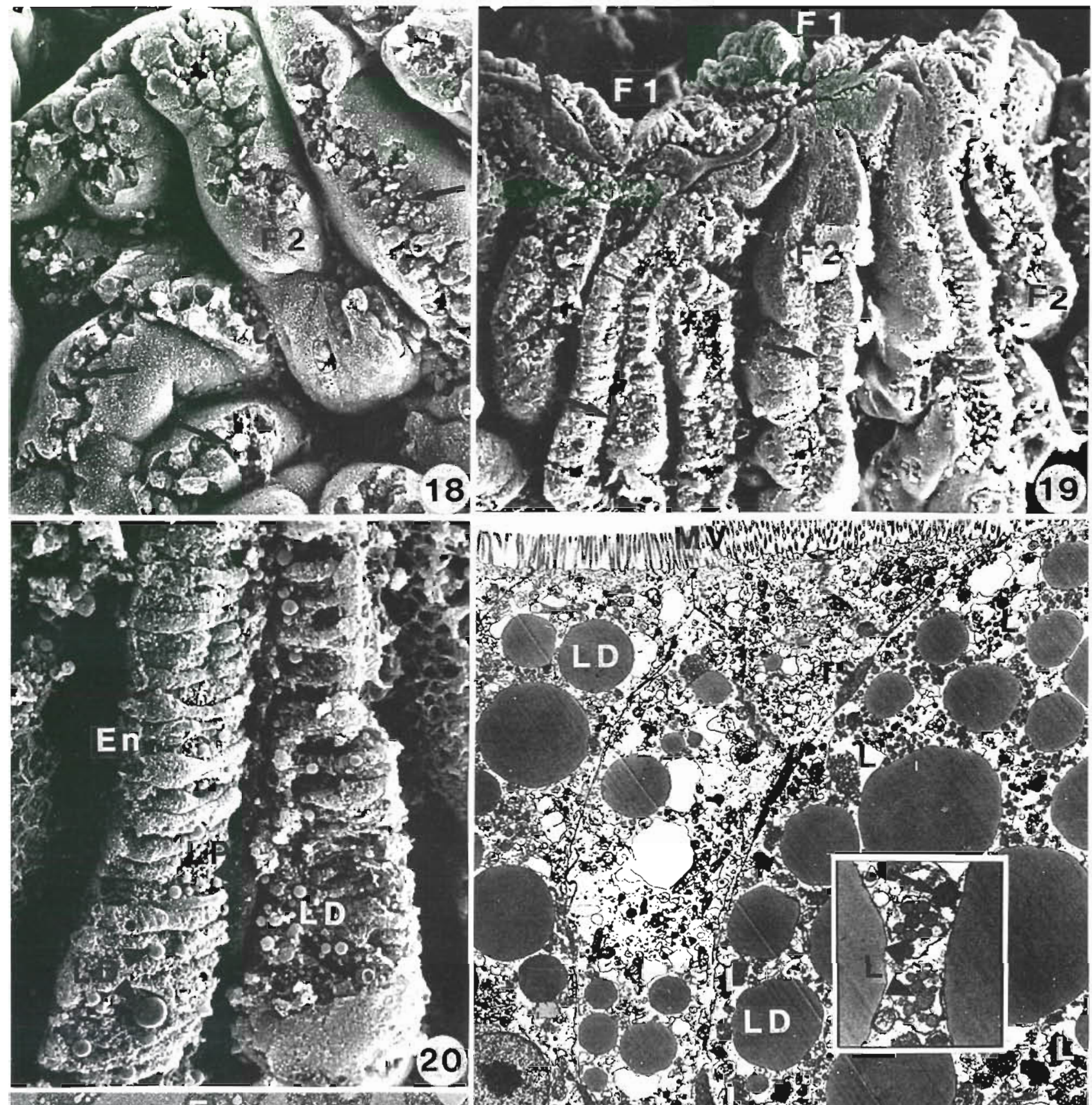

Dor
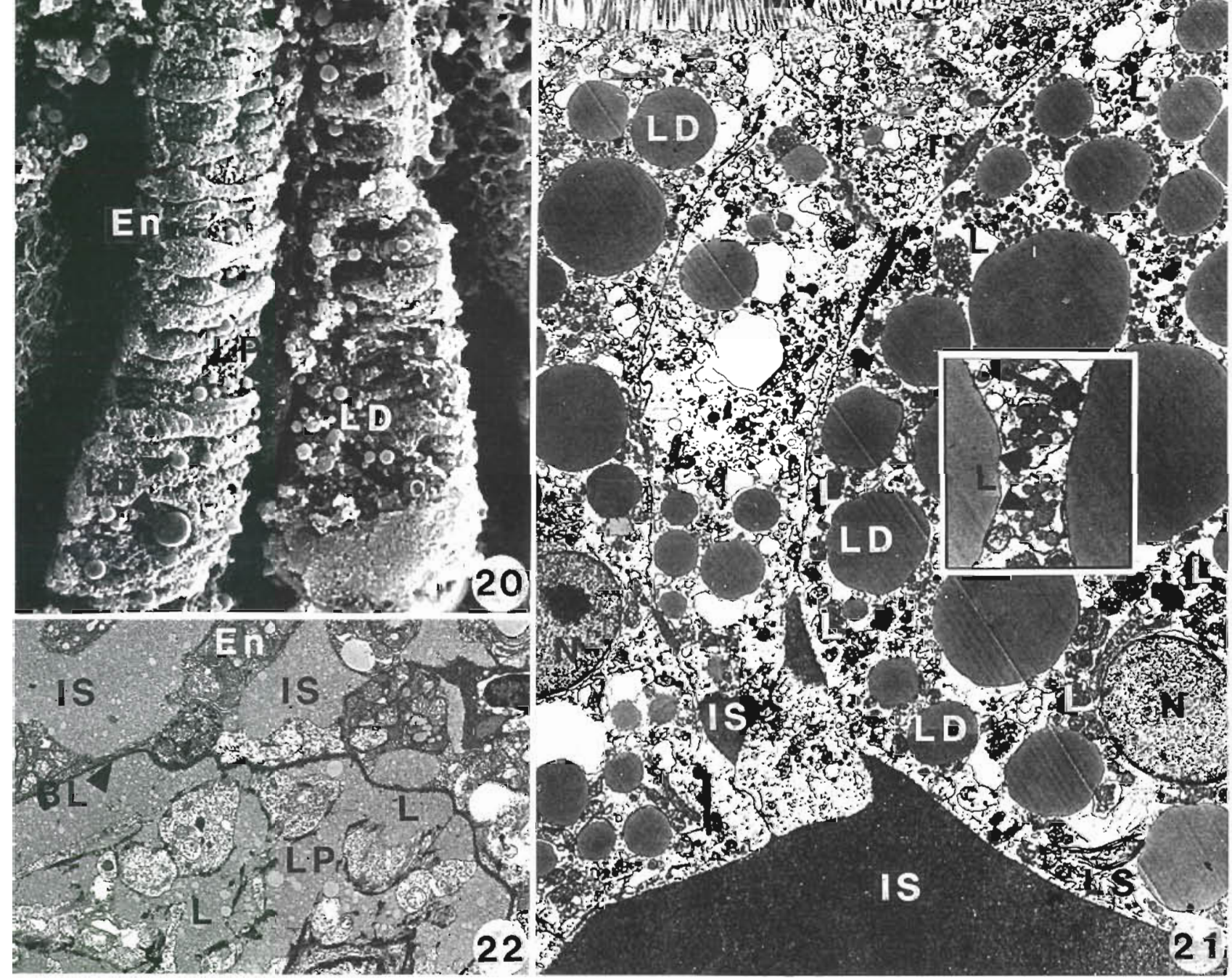

Figs. 12 to 22 (continued). Fig. 18. SEM of steatotic epithelium in the second degree of severity. The apical enterocytes of these

The stripping of the lamina propria (arrows), at the apex of primary and secondary folds (F1, F2), results from a marked cellular abrasion. Note the simplification of the second-order folds (compare with Fig. 1). ( $\times 170)$. Fig. 20. Higher magnification of a released from burst cells. ( $\times 630)$. Fig. 21. Ultrastructure of steatotic enterocytes in the second degree of severity. Lipid droplets (LD) and lipoproteic particles (L) are very abundant everywhere in the cytoplasm. Lipoproteic particles are contained, singly or
grouped, in Golgi or reticulum vesicles (Inset $[\times 14500]$. One of them reaches $350 \mathrm{~nm}$ in diameter (arrow). Intercellular spaces (IS) are also affected by the fatty overloading: they are abnormally and strongly enlarged at the bottom of the epithelium Undeveloped lamellar structures (LS) are stacked in the right-side of the micrograph. $(\times 3600)$. Fig. 22. Aspect of the lamina propria (LP) overloaded with lipoproteic particles (L) of heterogeneous sizes. Above the basal lamina (BL), the bottom of some 
transit across the intestinal mucosa was examined following the intake of strictly natural food both in terms of its origin and its quantitative and qualitative composition, which depends on selection by the fish. Despite the absence of precise data on the quantity of food ingested and the date of last feed, the feral bass constituted an authentic control affording optimal conditions for evaluating the pathological state of the cage-bred bass.

The enterocyte of the proximal intestine of the sea bass closely resembles that of other species, such as Carassius auratus and Salmo irideus (Yamamoto 1966), Cyprinus carpio, Tinca tinca and Perca fluviatilis (Noaillac-Depeyre \& Gas 1974, 1976, 1979) and Ctenopharyngodon idella (Stroband \& Debets 1978). It contains 2 categories of lipids, i.e. granular and 'stellate lipids' ('lipides étalés') or 'free' lipid droplets, as previously reported for Salmo gairdneri (Bergot \& Fléchon 1970a, b, Sire \& Vemier 1981), Cyprinus carpio, Tinca tinca and Perca fluviatilis (Noaillac-Depeyre \& Gas 1974, 1976, 1979). As concluded by Sire et al. (1981) for trout, the lipid granules in sea bass, whose diameter was less than $100 \mathrm{~nm}$, clearly correspond to VLDL comparable to those in mammals. The localization of these lipoproteins in the enterocytes and their immediate environment resembles the classic pattern of fat absorption. Certain of these granules appeared to be synthesized in the cavities of the endoplasmic reticulum, and accumulated in the saccules of supranuclear dictyosomes where vacuoles were released, sometimes attaining $1.5 \mu \mathrm{m}$ in diameter. The VLDLlike granules reached the interenterocytic spaces via the Golgi apparatus or directly from the endoplasmic reticulum. This transfer was probably facilitated by the laterobasal 'lamellar structures' characteristic of fish, which were much more numerous in the nourished fish than in the starved fish. This implies that membrane synthesis occurs in the enterocyte. The transit to the lamina propria was clearly very rapid, considering the low concentration of lipoproteins between the enterocytes. The reduced size of the granules presumably contributed to the speed of their evacuation, by favoring fluidity in the interstitial medium and passage through the basal layer.

The presence of lipid droplets, which remained limited in the feral bass, may indicate temporary storage of fatty acids in the form of triacylglycerols, as suggested by Bergot \& Flechon (1970b) for trout. In contrast, the absorbent cells in the proximal intestine of the cage-bred bass were the site of fat overloading, related essentially to the existence in the cytoplasm of bulky lipid droplets, as well as to the increase in the number and size of lipoprotein granules, whose diameter sometimes reached $400 \mathrm{~nm}$.

As mentioned above, the homogeneous lipid inclu- sions, variously called 'stellate lipids' or 'free' lipid droplets, are generally considered to be forms of temporary storage of excess fatty acids. Noaillac-Depeyre \& Gas (1976) attributed their formation in tench to deficient activity of the endoplasmic reticulum or to insufficient protein synthesis. Stroband \& Debets (1978), who observed in grass carp Ctenopharyngodon idella that the cells at the apex of the folds were more enriched in lipid globules than the others, proposed 2 explanations for the phenomenon: either the enterocytes farthest from the basal renewal zones have aged and can no longer assure the transfer of the lipids they absorb, or their position and physiological state favor increased absorption of fats, which causes overloading. Sire \& Vernier (1981) considered that the degree of fatty acid unsaturation has an intluence on the development of 'free' lipid droplets. Whatever causes the appearance of these stored lipids, their abundance in fish has never been considered to be a precursor of a pathological state. This cannot be said of the cage-bred sea bass, however, whose intestinal mucosa showed several degrees of degeneration due to hypertrophy and fatty degeneration of the enterocytes.

Cases of steatosis comparable to that of sea bass have been described in mammals, particularly in humans, in conjunction with a disturbance or deficiency of chylomicron synthesis and evacuation from the enterocyte. In human pathology, multiple causes have been found for this disturbance: defective protein synthesis in congenital lipoprotein-B deficiency (Dobbins 1966), structural and functional deterioration of absorbent cells in response to gluten intolerance during celiac disease (Rubin 1971), and enterocytic dysfunction resulting from insufficient formation of micelles during smallintestinal stasis syndrome (Ament et al. 1972). In healthy animals, fat overloading has been observed in immature or senescent duodenal epitheliocytes of the suckling rat (Berendsen \& Blanchette-Mackie 1979), in the distal region of the small intestine of the adult rat (Sabesin et al. 1975), and in the colon of the mouse (Snipes 1977). In these 3 cases, the enterocytes involved were characterized by their low natural capacity to synthesize lipoproteins and to export them. It should also be mentioned that experimental inhibition of protein synthesis in mammals results in an enlargement of enterocytic chylomicrons (Glickman et al. 1972) and to extensive development of lipid droplets (Sabesin \& Isselbacher 1965, Friedman \& Cardell 1972)

It thus appears that in fish and mammals, under both normal and pathological conditions, deficient lipoprotein synthesis is closely related to the accumulation of 'free' lipid droplets. This conclusion is difficult to apply to the cage-bred sea bass, because of the abundance of lipoprotein granules in its intestinal mucosa. However, we found that these granules were large and had a 
tendency to aggregate and form areas remaining in the enterocyte itself, the interenterocytic spaces, and all levels of the lamina propria. It is possible that the size of these lipoprotein granules impedes their evacuation, contributes to their aggregation, and thereby leads to an accumulation of triacylglycerols in the absorbent cells. The evacuation defect and consequent overloading are concomitant with general lipid saturation of the organism, which is dramatically expressed as liver steatosis and hyperdevelopment of the adipose tissue.

Obviously the primary cause of these phenomena is the inadequacy of the artificial food used in fish-farming, since sea bass specimens reared on natural feed, in the same environmental conditions, did not show any lipid overloading. Based on comparisons with trout, it would appear that the food is unbalanced with respect to the lipid fraction. For example, Bauermeister et al. (1979) observed that the enterocytes of trout nourished with marine zooplankton synthesize VLDL-like particles, sometimes grouped in conglomerates, and chylomicrons of medium size, but never 'free' lipid droplets. In the same species, a balanced diet results in the synthesis of VLDL and small chylomicrons (Sire et al. 1981), whereas a diet with excess lipids, comprising a large proportion of highly polyunsaturated fatty acids, is followed by the formation of large chylomicrons and the temporary appearance of 'free' lipid droplets (Sire \& Vernier 1981). In trout given food that differs to varying extents from natural food, morphological differences occur which are very similar to those observed in the feral and cage-bred sea bass. But although the intestinal mucosa of the experimental trout recovers normalcy after several hours, the enterocytes of caged sea bass are unable to evacuate their lipids, which leads to steatosis and ultimately to epithelial abrasion.

It thus appears that a persistent unsuitable diet is the cause of this digestive pathology. The unsuitability can be attributed to excessive fatty acids in the artificial feed, to excessive feeding facilitated by the consistency of the feed, which is abundantly provided, or to a deficiency in certain elements that are indispensable for the proper assimilation of lipids. For instance, it is well known that lecithins are important in the solubilization, absorption, and transport of fats in the mammalian intestine (O'Doherty et al. 1973, Rodgers 1975, Tso et al. 1977). One of lecithin components, choline, plays an essential role in lipid metabolism. Choline opposes fatty infiltration of the liver in the trout (Ketola 1976) and its insufficiency causes lipid droplets to appear in rat enterocytes (Takahashi \& Mizunuma 1984). In carnivorous fishes such as the sea bass, lecithins originating from the digestion of prey may facilitate the assimilation of fats. In contrast, cage-bred fish may lack lecithins and choline, and it is possible that this defi- ciency adds to the negative effects of the dietary excess mentioned above.

On the other hand, a possible toxicity of the artificial food, related to lipid oxidation, might affect the intestinal cell functions. However, the manufacturers warrant the good conservation of their product containing $\mathrm{C}$ and E vitamins. Thus, a toxic effect due to lipid rancidness is unlikely to occur.

Another factor to consider is the simplification of the intestinal contours following regression of the secondary folds in the cage-bred sea bass. This situation may coincide with a decrease in the number of regeneration sites in the epithelium, slowing the renewal of tissue, and resulting finally in cell aging. Older enterocytes would then have difficulty in assuring the transfer of fats in the form of chylomicrons, and they would become stored elements. The oldest cells, i.e. those at the apex of the folds, were indeed found to accumulate a maximum of lipid droplets

It should lastly be noted that the specimens with intestinal steatosis showed the same anomaly in the liver. Structural and functional disturbances of hepatocytes, as described by Bac et al. (1983), may impede the production of bile or diminish its quality, thereby negatively affecting intestinal lipid absorption. This hypothesis is supported by the observations of Langille \& Youson (1985) in adult lamprey, which does not evacuate bile into the intestine and whose enterocytes are packed with lipid droplets after feeding.

Thus, there are many possible causes for degenerative intestinal steatosis in the cage-bred sea bass. This pathological condition does not appear to be a cause for alarm, in view of the low mortality associated with it, but its total harmlessness still needs to be verified. A deteriorated intestinal mucosa no longer plays an effective role as a selective barrier. Certain molecules can penetrate the internal medium and provoke indirect disturbances that may be unfavorable to the human consumer. Moreover, the decrease in absorptive capacity could lead to feed wastage that is unprofitable to the breeder. Only long and rigorous experimentation will allow a clear determination of the factors responsible for this condition, and provide the basis for effective remedies to assure that the ensuing drawbacks can be avoided.

Acknowledgements. We thank the personnel of the IFREMER station, the Director Mr Ricard, and Mr Divanach, who provided us with numerous fish. We are grateful to $\mathrm{Mr}$ Noell for technical assistance.

\section{LITERATURE CITED}

Ament, M. E., Shimoda, S. S., Saunders, D. R., Rubin, C. E. (1972). Pathogenesis of steatorrhea in three cases of small intestinal stasis syndrome. Gastroenterology 63: 728-747 
Bac, N., Biagianti, S., Bruslé, J. (1983). Etude cytologique ultrastructurale des anomalies hépatiques du Loup, de la Daurade et de l'Anguille, induites par une alimentation artificielle. Actes Coll. $\mathrm{n}^{\circ} 1$, Bases Biol. Aquaculture IFREMER: $473-484$

Bauermeister, A. E. M., Pirie, B. J. S., Sargent, J. R. (1979). An electron microscopic study of lipid absorption in the pyloric cæca of rainbow trout (Salmo gairdneri) fed wax ester-rich zooplankton. Cell Tissue Res. 200: 475-486

Berendsen, P. B., Blanchette-Mackie, E. J. (1979). Milk lipid absorption and chylomicron production in the suckling rat. Anat. Rec. 195: 397-414

Bergot, P., Fléchon, J. E. (1970a). Forme et voie d'absorption intestinale des acides gras chez la truite arc-en-ciel (Salmo gairdneri Rich.). I. Lipides en particules. Annls Biol. anim. Biochim. Biophys. 10: 459-472

Bergot, P., Fléchon, J. E. (1970b). Forme et voie d'absorption intestinale des acides gras à chaine longue chez la truite arc-en ciel (Salmo gâirdneri Rich.). II. Lipides 'étalés' Annls Biol. anim. Biochim. Biophys. 10: 473-480

Diaz, J. P., Connes, R., Tudela-Moreau, C. (1987). Mise en évidence de lésions épithéliales digestives et olfactives chez les Poissons, au moyen du microscope électronique à balayage. Aquaculture 60: 1-11

Dobbins, W. O. (1966). An ultrastructural study of the intestinal mucosa in congenital B-lipoprotein deficiency with particular emphasis upon the intestinal absorptive cell. Gastroenterology 50: 195-210

Eckmann, R. (1985). Histopathological alterations in the intestine of whitefish (Coregonus sp.) larvae reared on zooplankton from Lake Constance. Dis. aquat. Org. 1: 11-17

Friedman, H. I., Cardell, R. R. (1972). Effects of puromycin on the structure of rat intestinal epithelial cells during fat absorption. J. Cell Biol. 52: 15-40

Friedman, H. I., Cardell, R. R. (1977). Alterations in the endoplasmic reticulum and golgi complex of intestinal epithelial cells during fat absorption and after termination of this process: a morphological and morphometric study. Anat. Rec. 188: 77-102

Glickman, R. M., Kirsch, K., Isselbacher, K. J. (1972). Fat absorption during inhibition of protein synthesis: studies of lymph chylomicrons. J. clin. Invest. 51: 356-363

Ketola, H. G. (1976). Choline mtabolism and nutritional requirement of lake trout (Salvelinus namaycush). J. Anim. Sci. 43: 474-477

Langille, R. M., Youson, J. H. (1985). Protein and lipid absorption in the intestinal mucosa of adult lampreys (Petromyzon marinus L.) following induced feeding. Can. J. Zool. 63: $691-702$

Noaillac-Depeyre, J., Gas, N. (1974). Fat absorption by the enterocytes of the carp (Cyprinus carpio L.). Cell Tissue Res. 155: 353-365

Noaillac-Depeyre, J., Gas, N. (1976). Electron microscopic study on gut epithelium of the tench (Tinca tinca L.) with respect to its absorptive functions. Tissue Cell 8: 511-530

Noaillac-Depeyre, J, Gas, N. (1979). Structure and function of the intestinal epithelial cells in the perch (Perca fluviatilis L.). Anat. Rec. 195: 621-640

O'Doherty, J. A., Kakis, G., Kuksis, A. (1973). Role of luminal lecithin in intestinal tat absorption. Lipids 8: 249-255

Rodgers, J. B. (1975). Lipid absorption in bile fistula rats lack of a requirement for biliary lecithin. Biochim. Biophys. Acta. 398: 92-100

Rubin, W. M. D. (1971). Celiac disease. Am. J. clin. Nutr. 24: 91-111

Sabesin, S. M., Holt, P. R., Clark, S. B. (1975). Intestinal lipid absorption evidence for an intrinsic defect of chylomicron secretion by normal rat distal intestine. Lipids 10: 840-846

Sabesin, S. M., Isselbacher, K. J. (1965). Protein synthesis inhibition: mechanism for the production of impaired fat absorption. Science 147: 1149-1151

Segner, H. (1985). Influence of starvation and refeeding with different diets on the hepatocyte ultrastructure of juvenile Siganus guttatus Bloch (Teleostei: Siganidae). Zool. Anz. 214: $81-90$

Segner, H., Burkhardt, P., Avila, E. M., Juario, J. V., Storch, V. (1987). Nutrition-related histopathology of the intestine of milkfish Chanos chanos fry. Dis. aquat. Org. 2: 99-107

Shimoda, S. S., Saunders, D. R., Rubin, C. E. (1968). The Zollinger-Ellison syndrome with steatorrhea. II. The mechanism of fat and vitamine B12 malabsorption. Gastroenterology 55: 705-723

Sire, M. F., Lutton, C., Vernier, J. M. (1981). New views on intestinal absorption of lipids in teleostean fishes: an ultrastructural and biochemical study in the rainbow trout. J. Lipid Res. 22: 81-94

Sire, M. F., Vernier, J. M. (1981). Etude ultrastructurale de la synthèse de chylomicrons au cours de l'absorption intestinale des lipides chez la truite. Influence de la nature des acides gras ingérés. Biol. cell. 40: 47-62

Snipes, R. L. (1968). The effects of essential fatty acid deficiency on the ultrastructure and functional capacity of the jejunal epithelium. Lab. Invest. 18: 179-189

Snipes, R. L. (1977). Limited fat absorption in the large intestine of mice. A morphological study. Acta Anat. 99: $435-439$

Storch, V., Segner, H., Juario, J. V., Duray, M. N. (1984). Influence of nutrition on the hepatocytes of Chanos chanos (Chanidae: Teleostei). Zool. Anz. 213: 151-160

Stroband, H.W. J., Debets, F. M. W. (1978). The ultrastructure and renewal of the intestinal epithelium of the juvenile grass carp (Ctenopharyngodon idella Val.). Cell Tissue Res. 187: 181-200

Takahashi, Y., Mizunuma, T (1984). Cytochemistry of the tat absorption. Int. Rev. Cytol. 89: 115-136

Tso, P., Balint, J A., Simmonds, W J. (1977). Role of biliary lecithin in lymphatic transport of fat. Gastroenterology 73 : $1362-1367$

Yamamoto, T (1966). An electron microscope study of the columnar epithelial cell in the intestine of fresh water Teleosts: Goldfish (Carassius auratus) and rainbow trout (Salmo irideus). Z. Zellfosch. mikrosk. Anat. 72: 66-87 